\title{
Heart Failure and Stroke
}

\author{
Katja Schumacher ${ }^{1,2}$. Jelena Kornej ${ }^{2,3} \cdot$ Eduard Shantsila $^{1}$ - Gregory Y. H. Lip ${ }^{1}$
}

Published online: 30 July 2018

(C) The Author(s) 2018

\begin{abstract}
Purpose Ischemic stroke significantly contributes to morbidity and mortality in heart failure (HF). The risk of stroke increases significantly, with coexisting atrial fibrillation (AF). An aggravating factor could be asymptomatic paroxysms of AF (so-called silent $\mathrm{AF}$ ), and therefore, the risk stratification in these patients remains difficult. This review provides an overview of stroke risk in HF, its risk stratification, and stroke prevention in these patients.

Recent Findings Stroke risk stratification in HF patients remains an important issue. Recently, the $\mathrm{CHA}_{2} \mathrm{DS}_{2}-\mathrm{VASc}$ score, originally developed to predict stroke risk in AF patients, had been reported to be a predictive for strokes in HF patients regardless of AF being present. Furthermore, there are several independent risk factors (e.g., hypertension, diabetes mellitus, prior stroke) described.

Summary Based on the current evidence, $\mathrm{HF}$ should be considered as an independent risk factor for stroke. The $\mathrm{CHA}_{2} \mathrm{DS}_{2}-\mathrm{VASc}$ score might be useful to predict stroke risk in HF patients with or without AF in clinical routine. However, there is only a recommendation for the oral anticoagulation use in patients with concomitant $\mathrm{HF}$ and $\mathrm{AF}$, while in patients with $\mathrm{HF}$ and no $\mathrm{AF}$, individualized risk stratification is preferred. Current guidelines recommend to prefer non-vitamin Kantagonist anticoagulants over warfarin.
\end{abstract}

Keywords Heart failure $\cdot$ Stroke $\cdot$ Silent atrial fibrillation $\cdot$ Risk stratification $\cdot$ Stroke prevention

\section{Introduction}

Heart failure (HF) is a frequent condition associated with diverse comorbidities such as cardiac arrhythmias, thromboembolism, impaired renal function, and an increased mortality as a result [1]. The prevalence of HF is approximately $1-2 \%$ of the adult population in developed countries with a higher percentage $(>10 \%)$ in the population age $>70$ years [1].

Katja Schumacher and Jelena Kornej contributed equally to this work.

This article is part of the Topical Collection on Comorbidities of Heart Failure

Gregory Y. H. Lip

g.y.h.lip@bham.ac.uk

1 Institute of Cardiovascular Sciences, University of Birmingham, Birmingham, UK

2 Heart Center, Department of Electrophysiology, University of Leipzig, Leipzig, Germany

3 Institute for Medical Informatics, Statistics and Epidemiology (IMISE), Leipzig University, Leipzig, Germany
An increased stroke risk in HF patients has been described in several studies [2]. Pathophysiologically, a predisposition to thromboembolism is caused by abnormal blood flow, abnormal vessel/chamber lining, and abnormal blood particles, also referred to as Virchow's triad [3]. Abnormal blood flow is evident in patients with HF because of left ventricular systolic dysfunction (LVSD) associated with left ventricular dilatation and abnormal (slowed) blood flow [4]. Given the fact that HF patients with preserved EF (HFpEF) also have an increased stroke risk $[5,6]$, such patients also exhibit flow abnormalities - apart from vessel wall changes (e.g., endothelial dysfunction) $[7,8]$ and abnormal blood constituents (e.g., platelet function) [9].

Atrial fibrillation $(\mathrm{AF})$ is the strongest independent risk factor for stroke, followed closely by HF [10]. Of note, HF and $\mathrm{AF}$ frequently coexist and exacerbate each other: while $\mathrm{AF}$ occurs in more than half $(57 \%)$ individuals with $\mathrm{HF}, \mathrm{HF}$ is present in over one third (37\%) of AF patients. These results had been shown in 1737 individuals with new AF and 1166 individuals with new HF from Framingham Heart Study [11]. Particularly, paroxysmal AF is mostly associated with stroke in comparison to persistent AF [12]. Problematically, patients 
are often unaware of these (often asymptomatic) paroxysmal $\mathrm{AF}$ attacks and remain underdiagnosed. Indeed, episodes of silent $\mathrm{AF}$ are present in approximately one third of the total population of patients with AF [13].

Given the high rates of hospitalization and lethality due to stroke in HF patients, there is a major clinical interest in stroke prediction. Several risk factors associated with an increased stroke risk (e.g., advanced age, prior stroke, diabetes mellitus) [14] have already been identified and were included into different risk models [15•]. The predictive value of the $\mathrm{CHA}_{2} \mathrm{DS}_{2}$-VASc score, originally designed for stroke prediction in AF patients, has also been shown in the HF population $[16 \bullet \bullet, 17]$.

While oral anticoagulation in $\mathrm{AF}$ is recommended dependent on the $\mathrm{CHA}_{2} \mathrm{DS}_{2}$-VASc score, current $\mathrm{HF}$ guidelines do not recommend oral anticoagulation for HF patients without documented AF. Indeed, there is an explicit recommendation for an oral anticoagulation only in patients with both HF and AF.

In this review, we discuss the risk of stroke in HF patients, distinguishing between HF with and without coexisting AF. Second, we debate the role of silent AF in these patients and, third, give an overview of risk stratification and therapy approaches.

\section{Search Strategy}

Electronic searches of English literature were performed in the PubMed database for relevant publications from 2000 to 2018 evaluating the risk of stroke in HF patients with and without $\mathrm{AF}$ as well as the role of silent AF, possibilities of risk stratification, and therapeutic implications. The following search terms were used in this review: "heart failure" AND/OR "stroke" AND/OR "atrial fibrillation" AND/OR "AF" AND/ OR "silent atrial fibrillation" AND/OR "epidemiology" AND/ OR "risk stratification" AND/OR "NOAC" AND/OR "warfarin." Articles were used when studies investigated abovementioned aspects or reviewed the current state of research of stroke in HF. Two authors (K.S. and J.K.) screened all the studies for qualification by abstract screening and fulltext reviewing.

\section{HF Epidemiology}

Over 40 million individuals have $\mathrm{HF}$, which is considered as the second most important risk factor for stroke after $\mathrm{AF}[10$, 18]. Of note, 10-24\% of patients with stroke have HF, while HF per se (without AF) appears to be the cause of stroke in $9 \%$ in comparison to $15 \%$ for $\mathrm{AF}$ per se and $2 \%$ for both $\mathrm{HF}$ and AF [19]. As mentioned above, analysis of Framingham Heart Study patients (participants with new-onset AF $(n=1737)$ and/or HF $(n=1166))$ showed that AF occurs in more than half $(57 \%)$ of the individuals with HF; HF is presented in over one third (37\%) of AF patients [11]. Nevertheless, data reporting the incidence of stroke in HF patients vary among studies with designs and populations [20].

Several clinical trials-Warfarin/Aspirin Study in Heart failure (WASH), HEart failure Long-term Antithrombotic Study (HELAS), Warfarin and Antiplatelet Therapy in Chronic Heart failure trial (WATCH), and Warfarin versus Aspirin in Reduced Cardiac Ejection Fraction trial (WARCEF) - investigating HF patients in sinus rhythm have reported a low incidence of stroke in their populations [21-23]. In the WATCH trial, the incidence of stroke ranged from $0.4 \%$ in the warfarin group to $2.3 \%$ in the aspirin plus clopidogrel group. In a community-based cohort of 630 patients, Witt et al. found that $16 \%$ of the HF patients (where $41 \%$ had AF) experienced an ischemic stroke [2]. Their stroke risk was 17.4-fold increased within first 30 days after the initial diagnosis and remained elevated during follow-up of 5 years [2]. In another study, Mujib reported an approximately $1 \%$ annual rate of stroke in HF patients with sinus rhythm, which was higher than in general population $(0.3 \%)$ [24] but lower than in those with both HF and AF. The presence of HF is associated with high mortality and hospitalization rates. Indeed, stroke patients with HF have longer hospitalization periods and a 2.0-2.5-fold higher mortality than patients without HF [2]. Stroke risk in HF patients seems to depend on HF severity: mild to moderate HF is associated with an annual stroke risk of $1.5 \%[25,26]$, while stroke risk in severe HF approaches $4 \%$ [27].

As mentioned, concomitant $\mathrm{HF}$ and $\mathrm{AF}$ are the cause of $2 \%$ of all strokes. The overall rate of stroke in $\mathrm{HF}$ without $\mathrm{AF}$ (1.6\% per year) is about one third of that seen in $\mathrm{AF}$ without HF (5\%) [19]. Of note, AF type could play an important role for the stroke occurrence in HF patients. However, the literature is controversial. On the one hand, persistent AF is described to not increase stroke risk in contrast to paroxysmal $\mathrm{AF}$ [12]. On the other hand, several studies reported an equal risk of stroke for paroxysmal and persistent AF [28] or even opposite results [29]. A meta-analysis including 18 papers with 134,847 AF patients [30] showed that the stroke risk was higher in patients with persistent AF with ORs of 0.75 (95\% confidence interval (CI) $0.61-0.93$ ) in studies with no oral anticoagulants and 0.77 (95\% CI $0.68-0.88)$ in studies with oral anticoagulants in all patients. Nevertheless, it remains unclear if AF type is an independent predictor of stroke or predicated on a different patient profile regarding risk factors and comorbidities [31]. Patients with paroxysmal AF are likely to be younger, with a lower prevalence of structural heart disease, major comorbidities, and also have lower estimated thromboembolic and bleeding risks [32]. Based on this knowledge, it seems more reasonable that persistent $\mathrm{AF}$ has the higher stroke risk. But paroxysmal AF remains often 
asymptomatic as well as undiagnosed and consequently untreated leading to a possible increased risk of cardioembolic events [33].

Four randomized clinical trials investigating the effect of non-vitamin $\mathrm{K}$ antagonist oral anticoagulants (NOACs) anticoagulants (NOACs) in AF patients have presented different data on the effect of concomitant HF and AF. Whereas the Apixaban for Reduction in Stroke and Other Thromboembolic Events in Atrial Fibrillation (ARISTOTLE) study [34] and the Rivaroxaban versus Warfarin in Nonvalvular Atrial Fibrillation (ROCKET AF) study [35] could not find a significant difference in risk rates for stroke in $\mathrm{AF}$ patients with and without $\mathrm{HF}$, the Effective aNticoaGulation with factor $\mathrm{xA}$ next GEneration in Atrial Fibrillation-Thrombolysis In Myocardial Infarction study 48 (ENGAGE AF TIMI 48) trial found an increased risk for patients with both $\mathrm{AF}$ and HF present [36]. In the Randomized Evaluation of LongTerm Anticoagulation Therapy (RE-LY) trial, there was a numerically higher incidence of stroke in patients with AF and HF compared to AF without HF, but this was nonsignificant after multivariable adjustment [37].

While both $\mathrm{HF}$ and $\mathrm{AF}$ are independent risk factors for stroke, the coexistence of both diseases increased the risk even more. Kang et al. reported a 3.5-fold increased risk for stroke in HF-only patients, while patients with $\mathrm{HF}+\mathrm{AF}$ had a fivefold risk in stroke [38]. A more recent study did not find any significant difference in stroke risk between HF patients with or without $\mathrm{AF}$ (incidence $=2.6 \%$ patients with $\mathrm{AF}$ vs $2.8 \%$ without AF) [39]. The presence of AF had been also attributed to play a role in stroke etiology, as patients with both HF and AF mostly experienced cardioembolic strokes regardless of the HF etiology. Of note, patients with HF but without AF have different stroke causes according to the HF etiology: for example, patients with dilated cardiomyopathy or valvular heart disease had more frequent cardioembolic strokes while those with coronary artery disease/hypertension tended to experience atherosclerotic and lacunar strokes [40].

\section{Heart Failure with Preserved Ejection Fraction}

Most of prior studies investigated the stroke risk in patients with $\mathrm{HF}$ and reduced ejection fraction (HFrEF); however, HF with preserved EF (HFpEF) had an increased risk for strokes as well $[5,6]$. Studies investigating the stroke risk in patients with HFpEF in comparison to HFrEF have generally found a similar stroke risk [41-45]. In contrast to HFpEF, the patients with HFrEF have a higher mortality [44, 45]. Cogswell et al. hypothesized a possible influence of undiagnosed (silent) paroxysmal AF on stroke risk in HFpEF patients, given that stroke risk in patients with $\mathrm{HFpEF}$ without $\mathrm{AF}$ and $\mathrm{HFpEF}$ with $\mathrm{AF}$ as well as AF-only was similar [5].

\section{Silent Atrial fibrillation in HF}

Atrial fibrillation is the most common cardiac arrhythmia [46] and the strongest risk factor for the thromboembolic stroke [10]. Because of a high prevalence of paroxysmal AF in patients with acute stroke [12], more extensive diagnostic approaches to reveal paroxysmal AF episodes are needed [47]. This is aggravated by the fact that one third of patients with $\mathrm{AF}$ are not aware of its presence; hence, the term "silent AF" has been introduced.

Silent AF is often discovered after serious cerebro- and cardiovascular complications such as ischemic stroke and HF via routine self-monitoring of the pulse, 12-lead electrocardiogram (ECG), 24-h Holter ECG [13], implanted pacemakers, and defibrillators. In this context, attention has been directed towards AF burden, defined by time spent in AF per unit of time [48]. Several studies analyzing implanted devices showed that $20-42 \%$ of HF patients have silent AF episodes [49-51]. Silent AF was also common (10\%) at the acute phase of ischemic stroke or transient ischemic attacks (TIAs) [52]; $46 \%$ of patients suffering a cryptogenic stroke had silent AF on continuous electrocardiographic monitoring [33]. Of note, stroke incidence in silent AF is significantly higher in patients with multiple risk factors, especially hypertension, advanced age, obesity, diabetes mellitus, smoking, and previous cardiac disease [53-55] and in those with higher $\mathrm{CHA}_{2} \mathrm{DS}_{2}$-VASc score [56].

The presence of silent AF had been also described in patients with coronary artery disease and myocardial infarction [57]. Turakhia et al. found a threefold higher rate of cardiovascular death and a fivefold higher rate of hospitalization for $\mathrm{HF}$ in patients with silent $\mathrm{AF}$ [58]. In this context, silent AF was also common after coronary artery bypass grafting (a third had recorded AF episodes) [59]. The fact that silent AF is a common finding in different populations leads to the assumption that it could also play a role in stroke development in HF patients.

\section{Risk Stratification of Stroke in HF}

Because of the high prevalence of HF in the population and the associated stroke risk, there is interest in stroke prediction and evaluation of the possible need of antithrombotic therapy (Fig. 1).

The $\mathrm{CHA}_{2} \mathrm{DS}_{2}$-VASc score is widely used to estimate the risk of stroke in AF patients and to help in decision-making regarding oral anticoagulation [60]. In a nationwide prospective cohort of 42.987 patients with HF, Melgaard et al. demonstrated that $\mathrm{CHA}_{2} \mathrm{DS}_{2}$-VASc score has also predictive power for stroke, regardless of AF presence [16••]. Similar results have been found by Wolsk and colleagues in the Danish registry of 136,545 HF patients (with or without AF) [17] and in 


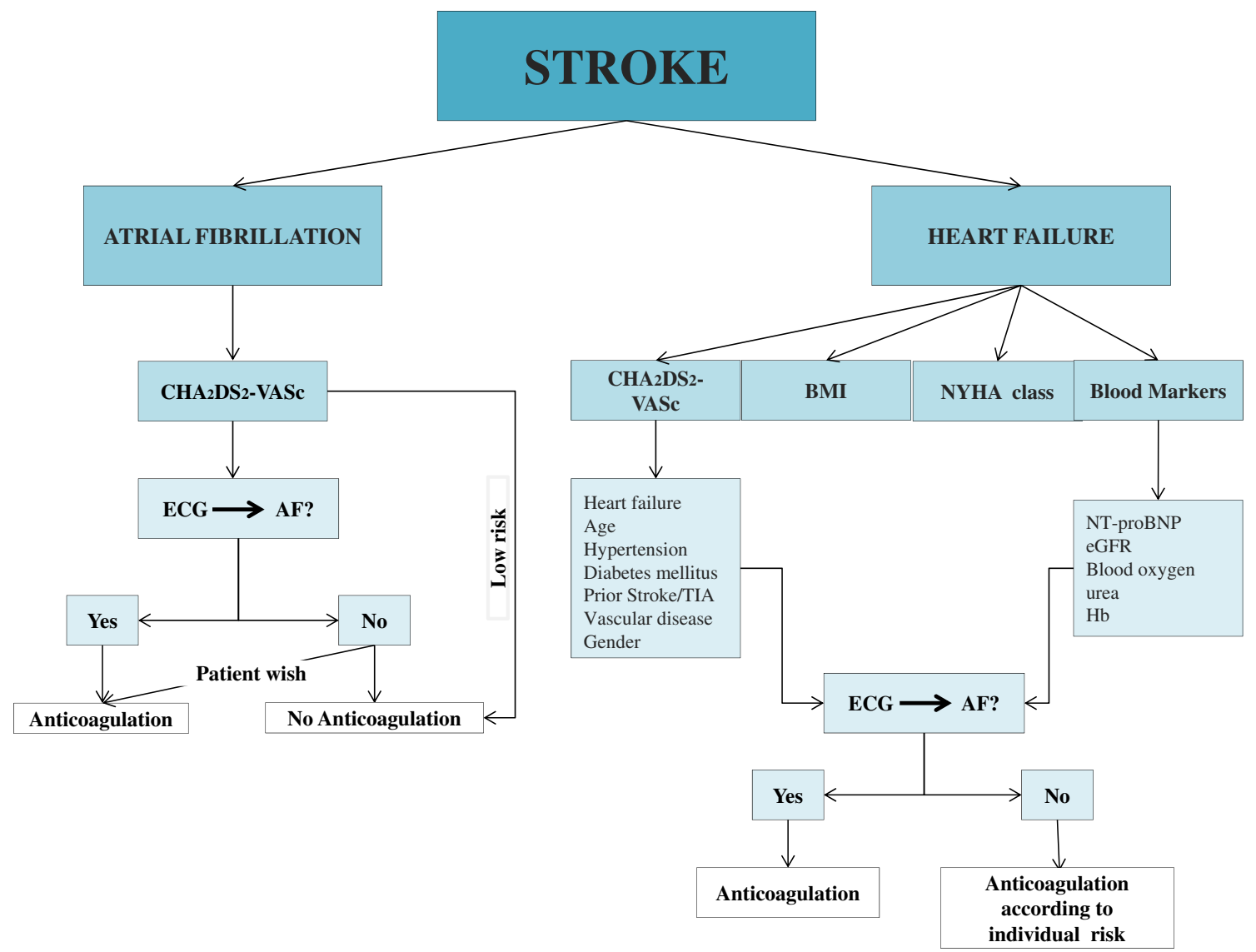

Fig. 1 Risk factors for stroke in patients with heart failure. Abbreviations: $\mathrm{AF}$, atrial fibrillation; BMI, body mass index; NYHA class, New York Heart Association class; TIA, transient ischemic attack; NT-proBNP, N-

the WARCEF cohort [61]. The studies support consideration of the $\mathrm{CHA}_{2} \mathrm{DS}_{2}$-VASc score for prediction of the risk of stroke in HF irrespective of AF presence. Indeed, several studies examined the components of the $\mathrm{CHA}_{2} \mathrm{DS}_{2}$-VASc score and demonstrated their individual association with stroke in HF: congestive HF represented by a decreased ejection fraction (hazard ratio [HR] 0.98-2.15) [15•, 34, 62, 63], hypertension (HR 1.18) [15•, 62, 64, 65], age (HR 1.34-1.35) [14, 15•, 62-64], diabetes mellitus (HR 1.114-1.87) [14, 15•, 16••, 62, 63, 65], prior stroke/TIA (HR 1.81-2.68) [14, 15•, 39, 63, 64], vascular disease (HR 1.34) [66], and gender (HR 0.569) [15•, $62,63]$. In WARCEF sub-study with patients with sinus rhythm, the ejection fraction was associated with stroke only if its baseline values were less than $15 \%[62,63]$.

However, the data are inconsistent. For example, McMurray et al. did not find a correlation between ejection fraction and stroke risk despite numerically higher rate of stroke and systemic embolism in patients with left ventricular systolic dysfunction [34]. Prior stroke [14, 15•, 39, 62, 64], gender [15•], and also peripheral artery disease [66] are associated with stroke risk in HF patients. Nevertheless, the correlation between stroke risk and age $[14,15 \cdot, 64]$ in $\mathrm{HF}$ terminal prohormone of brain natriuretic peptide; eGFR, estimated glomerular filtration rate; $\mathrm{Hb}$, hemoglobin

patients as well as those with diabetes mellitus $[15 \bullet, 16 \bullet \bullet$, 65] and hypertension are conflicting [62].

Although there are many different scores predicting the mortality in $\mathrm{HF}$ [67-69], the $\mathrm{CHA}_{2} \mathrm{DS}_{2}$-VASc score is the only one shown to be useful for stroke prediction in HF. Due to the lack of a convenient and accurate model to predict stroke and the accompanied increased mortality in HF, Freudenberger et al. proposed a new scoring system for stroke prediction in patients with an ejection fraction of less $35 \%$, with a full model of their score, including 14 risk factors, and to provide better clinical practicability a simpler more practical score of only eight of these components: age, blood oxygen urea, ejection fraction, hemoglobin, gender, diastolic blood pressure, diabetes mellitus, and prior stroke. In their study population $(n=2305)$, the new developed score performed modestly but was superior (statistically) to $\mathrm{CHA}_{2} \mathrm{DS}_{2}$-VASc score in stroke prediction (area under the curve [AUC] $0.660,95 \%$ CI $0.58-0.74$ vs $0.52,95 \%$ CI $0.398-0.63, p=0.001$ ) [15•].

Several studies investigated the impact of renal function on stroke risk in HF. Melgaard et al. showed an increased risk of ischemic stroke and intracranial bleeding in HF patients with stable chronic kidney disease, but this association could only 
Table 1 Warfarin vs antiplatelet therapy in patients with sinus rhythm

\begin{tabular}{|c|c|c|c|c|}
\hline & WASH & HELAS & WATCH & WARCEF \\
\hline $\begin{array}{l}\text { Year of } \\
\text { publication }\end{array}$ & 2004 & 2006 & 2009 & 2012 \\
\hline $\begin{array}{c}\text { Number of } \\
\text { patients }\end{array}$ & 279 & 197 & 1587 & 2305 \\
\hline $\begin{array}{l}\text { Treatment } \\
\text { arms }\end{array}$ & $\begin{array}{l}\text { Aspirin vs warfarin } \\
\text { Placebo } 99 \\
\text { Aspirin }(300 \mathrm{mg}) 91 \\
\text { Warfarin (INR 2-3) } 89\end{array}$ & $\begin{array}{l}\text { Aspirin vs warfarin } \\
\text { Ischemic Heart disease: } 61 \text { Aspirin } \\
\text { (325 mg) } 54 \text { Warfarin (INR 2-3) } \\
\text { Dilatative cardiomyopathy: } 38 \\
\text { Warfarin (INR 2-3) } 44 \text { Placebo }\end{array}$ & $\begin{array}{l}\text { Aspirin/clopidogrel vs } \\
\quad \text { warfarin } 523 \\
\text { Aspirin (162 mg) } 524 \\
\text { Clopidogrel (75 mg) } 540 \\
\text { Warfarin (INR 2.5-3) }\end{array}$ & $\begin{array}{l}\text { Aspirin vs warfarin } 1163 \\
\text { Aspirin (325 mg) } 1142 \\
\text { Warfarin (INR 2.5-3) }\end{array}$ \\
\hline $\mathrm{AF}$ & ca. $6 \%$ (baseline) & $\begin{array}{l}\text { None (exclusion criteria, patients } \\
\text { with AF in follow-up were } \\
\text { withdrawn) }\end{array}$ & $10 \%$ (follow-up) & ca. $4 \%$ (baseline) \\
\hline $\begin{array}{l}\text { Follow-up } \\
\text { (mean) }\end{array}$ & 27 months & ca. 20 months & 21 months & 3.5 years \\
\hline $\begin{array}{l}\text { Primary } \\
\text { endpoints }\end{array}$ & $\begin{array}{l}\text { Composite of } \\
\text { (1) death } \\
\text { (2) non-fatal myocardial } \\
\text { infarction } \\
\text { (3) non-fatal stroke }\end{array}$ & $\begin{array}{l}\text { Composite of } \\
\text { (1) non-fatal stroke } \\
\text { (2) peripheral or pulmonary } \\
\text { embolism } \\
\text { (3) myocardial (re)infarction } \\
\text { (4) re-hospitalization } \\
\text { (5) exacerbation of heart failure } \\
\text { (6) death from any cause }\end{array}$ & $\begin{array}{l}\text { Composite of } \\
\text { (1) all-cause mortality } \\
\text { (2) non-fatal myocardial } \\
\text { infarction } \\
\text { (3) non-fatal stroke }\end{array}$ & $\begin{array}{l}\text { Composite of } \\
\text { (1) ischemic stroke } \\
\text { (2) intracerebral hemorrhage } \\
\text { (3) death from any cause }\end{array}$ \\
\hline $\begin{array}{l}\text { Secondary } \\
\text { endpoints }\end{array}$ & $\begin{array}{l}\text { (1) Death or cardiovascular } \\
\text { hospitalization (incl. major } \\
\text { hemorrhage) } \\
\text { (2) Death or all-cause } \\
\text { hospitalization } \\
\text { (3) Total number of } \\
\text { hospitalization } \\
\text { (4) Composite of death, } \\
\text { cardiovascular } \\
\text { hospitalization and increase } \\
\text { in diuretic therapy for } \\
\text { worsening heart failure }\end{array}$ & $\begin{array}{l}\text { (1) Cardiac and total mortality } \\
\text { (2) Myocardial infarction or } \\
\text { re-infarction } \\
\text { (3) Heart failure exacerbation }\end{array}$ & $\begin{array}{l}\text { (1) All-cause mortality } \\
\text { (2) Nonfatal myocardial } \\
\text { infarction } \\
\text { (3) Nonfatal stroke } \\
\text { (4) Hospitalization for } \\
\text { heart failure }\end{array}$ & $\begin{array}{l}\text { Composite of } \\
\text { (1) primary outcome } \\
\text { (2) myocardial infarction } \\
\text { (3) hospitalization for heart failure }\end{array}$ \\
\hline $\begin{array}{l}\text { Safety } \\
\text { endpoints }\end{array}$ & $\begin{array}{l}\text { Included in secondary } \\
\text { endpoints }\end{array}$ & $\begin{array}{l}\text { Intracranial hemorrhage, incidence } \\
\text { of bleeding while on study drug, } \\
\text { differences in bleeding index on } \\
\text { study drug }\end{array}$ & Major bleeding & Major bleeding, minor bleeding \\
\hline Results & $\begin{array}{l}\text { Neither warfarin nor aspirin } \\
\text { reduces risk of stroke in } \\
\text { patients with HF }\end{array}$ & $\begin{array}{l}\text { Neither warfarin nor aspirin reduced } \\
\text { risk of stroke in patients with } \mathrm{HF} \\
\text { and without } \mathrm{AF}\end{array}$ & $\begin{array}{l}\text { Warfarin reduced stroke } \\
\text { more than aspirin or } \\
\text { clopidogrel but with a } \\
\text { higher risk of bleeding }\end{array}$ & $\begin{array}{l}\text { Warfarin was superior to aspirin } \\
\text { concerning ischemic stroke but is } \\
\text { accompanied with higher rates of } \\
\text { intracerebral hemorrhages }\end{array}$ \\
\hline
\end{tabular}

be found in patients without renal replacement therapy [70]. These findings are in agreement with the results of another study showing an association between estimated glomerular filtration rate and stroke risk in HF patients [64].

\section{Therapy}

Given the increased risk of thromboembolic complications in patients with HF, anticoagulation should be considered in these patients also in the absence of AF. Nevertheless, current guidelines do not recommend anticoagulation for patients with HF in general [1].

\section{Vitamin K Antagonists}

There are four randomized clinical trials investigating the effect of Warfarin on stroke risk in patients with HF in comparison to aspirin: WASH [21], HELAS [22], WATCH [23], and WARCEF [71]. Details of the trials are summarized in Table 1.

The WASH and HELAS trials were small studies, which were underpowered but showed no suggestion for the efficacy of anticoagulant therapy for HF patients in sinus rhythm [21, $22,72]$. The WATCH and WARCEF trials were larger studies (with WARCEF being a double-blind trial) and showed no significant benefit for the primary outcome that included mortality but a significant risk reduction for stroke (a secondary 
Table 2 Efficacy and safety of non-vitamin $\mathrm{K}$ antagonist oral anticoagulants in patients with atrial fibrillation and heart failure

\begin{tabular}{|c|c|c|c|c|}
\hline Sub-studies & RE-LY & ARISTOTLE & ROCKET-AF & ENGAGE AF \\
\hline $\begin{array}{l}\text { Year of } \\
\text { publication }\end{array}$ & 2013 & 2013 & 2013 & 2016 \\
\hline $\begin{array}{c}\text { Number of } \\
\text { patients }\end{array}$ & $\begin{array}{l}18.113 \\
4.904 \text { with } \mathrm{HF} \\
13.209 \text { without HF }\end{array}$ & $\begin{array}{l}14.671 \\
3.207 \text { with } \mathrm{HF}(\mathrm{EF}>40 \%) \\
2736 \text { with } \mathrm{HF}(\mathrm{EF}<40 \%) \\
8728 \text { without } \mathrm{HF}\end{array}$ & $\begin{array}{l}14.171 \\
9.033 \text { with } \mathrm{HF} \\
5.138 \text { without } \mathrm{HF}\end{array}$ & $\begin{array}{l}14.071 \\
6.344 \text { HF HYHA I-II } \\
1801 \text { NYHA III-IV } \\
5.926 \text { without HF }\end{array}$ \\
\hline $\begin{array}{l}\text { Treatment } \\
\text { arms }\end{array}$ & Dabigatran vs warfarin & Apixaban vs warfarin & Rivaroxaban vs warfarin & Edoxaban vs warfarin \\
\hline $\begin{array}{l}\text { Follow-up } \\
\text { (median) }\end{array}$ & 2.0 years & 18 months & 707 days & 2.8 years \\
\hline $\begin{array}{l}\text { Primary } \\
\text { endpoints }\end{array}$ & $\begin{array}{l}\text { (1) Stroke (ischemic or } \\
\text { hemorrhagic) } \\
\text { (2) Systemic embolism }\end{array}$ & $\begin{array}{l}\text { (1) Stroke (ischemic or } \\
\text { hemorrhagic) } \\
\text { (2) Systemic embolism }\end{array}$ & $\begin{array}{l}\text { (1) Stroke (ischemic or } \\
\text { hemorrhagic) } \\
\text { (2) Noncentral nervous system } \\
\text { embolism }\end{array}$ & $\begin{array}{l}\text { (1) Stroke (ischemic or } \\
\text { hemorrhagic) } \\
\text { (2) Systemic embolism }\end{array}$ \\
\hline $\begin{array}{l}\text { Secondary } \\
\text { endpoints }\end{array}$ & $\begin{array}{l}\text { (1) Vascular death } \\
\text { (2) Hospitalization } \\
\text { (3) Intracranial bleeding } \\
\text { (4) Total bleeding }\end{array}$ & $\begin{array}{l}\text { (1) Composite of } \\
\text { - Stroke } \\
\text { - Systemic embolism } \\
\text { - Death } \\
\text { (2) Net clinical benefit } \\
\text { composite of } \\
\text { - Stroke } \\
\text { - Systemic embolism } \\
\text { - Major bleeding } \\
\text { - Death from any cause }\end{array}$ & $\begin{array}{l}\text { (1) All-cause death } \\
\text { (2) Myocardial infarction } \\
\text { (3) Composite of } \\
\text { - Stroke } \\
\text { - Systemic embolism } \\
\text { - Vascular death }\end{array}$ & $\begin{array}{l}\text { (1) Ischemic stroke } \\
\text { (2) Hemorrhagic stroke } \\
\text { (3) Cardiovascular death } \\
\text { (4) Cardiovascular } \\
\text { hospitalization } \\
\text { (5) All-cause death }\end{array}$ \\
\hline $\begin{array}{l}\text { Safety } \\
\quad \text { endpoints }\end{array}$ & Major bleeding & Major bleeding & $\begin{array}{l}\text { (1) Primary: major or non-major } \\
\text { clinical relevant bleeding } \\
\text { (2) Secondary: intracranial } \\
\text { hemorrhage and hemorrhagic } \\
\text { stroke }\end{array}$ & Major bleeding \\
\hline Results & $\begin{array}{l}\text { Dabigatran was superior to } \\
\text { warfarin concerning stroke } \\
\text { (annual rate } 1.44 \text { vs } 1.92 \% \text { ) } \\
\text { and bleeding risk (annual rate } \\
3.10 \text { vs } 3.90 \% \text { ). No } \\
\text { differences in efficacy and } \\
\text { safety between HF and } \\
\text { No-HF }\end{array}$ & $\begin{array}{l}\text { Apixaban reduced risk for } \\
\text { stroke (HR 0.89, } 95 \% \text { CI } \\
0.81-0.98) / \text { bleeding/death } \\
\text { (HR } 0.85,95 \% \text { CI } 0.78-0.92 \text { ) } \\
\text { more than warfarin } \\
\text { independently of presence of } \\
\text { HF }\end{array}$ & $\begin{array}{l}\text { Rivaroxaban was non-inferior to } \\
\text { warfarin concerning efficacy } \\
\text { (HR 0.94, 95\% CI } 0.76-1.17 \text { ) } \\
\text { and safety (HR } 1.05,95 \% \text { CI } \\
0.95-1.15 \text { ) there was no } \\
\text { difference between HF and } \\
\text { No-HF }\end{array}$ & $\begin{array}{l}\text { Edoxaban was non-inferior to } \\
\text { warfarin concerning efficacy } \\
\text { (stroke in no HF: HR 0.87, } \\
\text { 95\% CI 0.69-1.11, NYHA } \\
\text { III-IV: HR 0.83, 95\% CI } \\
0.55-1.25 \text { ) and even more } \\
\text { safe (major bleeding in } \\
\text { no-HF: HR 0.82, 95\% CI } \\
0.68-0.99, \text { NYHA III-IV: } \\
\text { HR } 0.79,95 \% \text { CI } 0.54-1.17 \text { ), } \\
\text { there was no difference } \\
\text { between HF and No-HF }\end{array}$ \\
\hline
\end{tabular}

outcome) in patients treated with warfarin compared to aspirin; however, the positive effect was neutralized by an increased risk of major bleeding [23, 71]. In WATCH, clopidogrel was superior neither to warfarin nor to aspirin [23].

A meta-analysis of these four trials based on 3665 patients showed that warfarin reduced the risk of cardiovascular events including stroke by $20 \%$ compared to antiplatelet therapy (risk ratio (RR) $0.79,95 \%$ CI $0.63-1.00 ; I^{2}=0 \%$ ), but the risk of major bleeding was twofold higher (RR 2.00, 95\% CI 1.44-2.78; $I^{2}=4 \%$ ). Consequently, the stroke risk reduction of warfarin was outweighed by the increased bleeding risk [73••]. Interestingly, there was no significant increase of intracranial hemorrhage on warfarin compared to antiplatelet therapy [74].

\section{Non-Vitamin K Antagonists}

The efficacy and safety of these anticoagulation drugs were shown in AF patients in four randomized double-blind trials: RE-LY, ARISTOTLE, ROCKET AF, and ENGAGE AF [75-78].

In subgroup analyses, the effect of NOACs had been investigated in AF patients with and without HF (Table 2). In summary, NOACs (dabigatran [37], apixaban [34], or at least noninferior rivaroxaban [35] and edoxaban [36]) showed relative efficacy and safety compared to warfarin; however, there were no differences between patients with and without HF. Based on these results, current HF management guidelines recommend to prefer NOACs over warfarin in patients with concomitant $\mathrm{HF}$ and $\mathrm{AF}[1]$. 
A meta-analysis of RE-LY, ARISTOTLE, and ROCKET AF including 19,122 subjects showed a significant risk reduction for stroke in patients with both $\mathrm{HF}$ and $\mathrm{AF}$ combined with a decreased bleeding risk; in HF patients, NOACs were similar effective or even safer compared to those without HF [79].

However, it remains unclear whether NOACs have a positive impact of stroke risk reduction in patients with HF but in sinus rhythm. This question had been addressed in a randomized, double-blind, placebo-controlled trial (COMMANDER $\mathrm{HF}$ ) investigating the efficacy and safety of rivaroxaban vs placebo in HF patients without AF, where HF is related to ischemic heart disease and all patients are taking aspirin therapy [80].

\section{Current Approach}

Based on RE-LY, ARISTOTLE, ROCKET AF, and ENGAGE AF, European HF management guidelines recommend anticoagulation in patients with both $\mathrm{HF}$ and $\mathrm{AF}$, with a preference for NOACs [1]. Because of an increased bleeding risk outweighing the stroke risk reduction using warfarin in patients with HF but without AF $[20-23,71]$, the therapy of these patients needs to be tailored to the individual risk profile (e.g., prior stroke, cardiac thrombi) [1].

\section{Conclusions}

Based on the current evidence, HF should be considered as an independent risk factor for stroke. The $\mathrm{CHA}_{2} \mathrm{DS}_{2}$-VASc score might be useful to predict stroke risk in HF patients with or without AF in clinical routine.

Thus far, there is only a recommendation for the oral anticoagulation use in patients with concomitant $\mathrm{HF}$ and $\mathrm{AF}$, while in patients with $\mathrm{HF}$ and no $\mathrm{AF}$, individualized risk stratification is preferred. Based on recent data, NOACs should be preferred over warfarin. Finally, the results of ongoing studies may clarify further aspects of anticoagulation in HF patients without AF.

\section{Compliance with Ethical Standards}

Conflict of Interest Katja Schumacher, Jelena Kornej, and Eduard Shantsila each declare no potential conflicts of interest.

Gregory Y.H. Lip reports personal fees from Bayer, Bayer/Janssen, BMS/Pfizer, Biotronik, Medtronic, Boehringer Ingelheim, Microlife, Roche, and Daiichi-Sankyo. No fees are directly received personally.

Human and Animal Rights and Informed Consent This article does not contain any studies with human or animal subjects performed by any of the authors.
Open Access This article is distributed under the terms of the Creative Commons Attribution 4.0 International License (http:// creativecommons.org/licenses/by/4.0/), which permits unrestricted use, distribution, and reproduction in any medium, provided you give appropriate credit to the original author(s) and the source, provide a link to the Creative Commons license, and indicate if changes were made.

\section{References}

Papers of particular interest, published recently, have been highlighted as:

- Of importance

•- Of major importance

1 Ponikowski P, Voors AA, Anker SD, Bueno H, Cleland JGF, Coats AJS, et al. 2016 ESC guidelines for the diagnosis and treatment of acute and chronic heart failure. Rev Esp Cardiol (Engl Ed). 2016;69: 1167.

2 Witt BJ, Brown RD, Jacobsen SJ, Weston SA, Ballman KV, Meverden RA, et al. Ischemic stroke after heart failure: a community-based study. Am Heart J. 2006;152:102-9.

3 Watson T, Shantsila E, Lip GY. Mechanisms of thrombogenesis in atrial fibrillation: Virchow's triad revisited. Lancet. 2009;373:15566.

4 Hays AG, Sacco RL, Rundek T, Sciacca RR, Jin Z, Liu R, et al. Left ventricular systolic dysfunction and the risk of ischemic stroke in a multiethnic population. Stroke. 2006;37:1715-9.

5 Cogswell RJ, Norby FL, Gottesman RF, Chen LY, Solomon S, Shah A, et al. High prevalence of subclinical cerebral infarction in patients with heart failure with preserved ejection fraction. Eur J Heart Fail. 2017;19:1303-9.

6 Jang SJ, Kim MS, Park HJ, Han S, Kang DH, Song JK, et al. Impact of heart failure with normal ejection fraction on the occurrence of ischaemic stroke in patients with atrial fibrillation. Heart. 2013;99: $17-21$.

7 Chong AY, Blann AD, Patel J, Freestone B, Hughes E, Lip GY. Endothelial dysfunction and damage in congestive heart failure: relation of flow-mediated dilation to circulating endothelial cells, plasma indexes of endothelial damage, and brain natriuretic peptide. Circulation. 2004;110:1794-8.

8 Gibbs CR, Blann AD, Watson RD, Lip GY. Abnormalities of hemorheological, endothelial, and platelet function in patients with chronic heart failure in sinus rhythm: effects of angiotensinconverting enzyme inhibitor and beta-blocker therapy. Circulation. 2001;103:1746-51.

9 Pisters R, Lip GY. Safety and efficacy of new anticoagulants in patients with heart failure. Curr Heart Fail Rep. 2013;10:18-25.

10 Appelros P, Nydevik I, Seiger A, Terént A. Predictors of severe stroke: influence of preexisting dementia and cardiac disorders. Stroke. 2002;33:2357-62.

11 Santhanakrishnan R, Wang N, Larson MG, Magnani JW, McManus $\mathrm{DD}$, Lubitz SA, et al. Atrial fibrillation begets heart failure and vice versa: temporal associations and differences in preserved versus reduced ejection fraction. Circulation. 2016;133:484-92.

12 Rizos T, Wagner A, Jenetzky E, Ringleb PA, Becker R, Hacke W, et al. Paroxysmal atrial fibrillation is more prevalent than persistent atrial fibrillation in acute stroke and transient ischemic attack patients. Cerebrovasc Dis. 2011;32:276-82.

13 Dobreanu D, Svendsen JH, Lewalter T, Hernández-Madrid A, Lip GY, Blomström-Lundqvist $\mathrm{C}$, et al. Current practice for diagnosis 
and management of silent atrial fibrillation: results of the European Heart Rhythm Association survey. Europace. 2013;15:1223-5.

14 Abdul-Rahim AH, Perez AC, Fulton RL, Jhund PS, Latini R, Tognoni G, et al. Risk of stroke in chronic heart failure patients without atrial fibrillation: analysis of the controlled Rosuvastatin in Multinational Trial Heart Failure (CORONA) and the Gruppo Italiano per lo Studio della Sopravvivenza nell'Insufficienza Cardiaca-Heart Failure (GISSI-HF) Trials. Circulation. 2015;131: 1486-94. discussion 1494

15. Freudenberger RS, Cheng B, Mann DL, Thompson JL, Sacco RL, Buchsbaum R, et al. The first prognostic model for stroke and death in patients with systolic heart failure. J Cardiol. 2016;68:100-3. This article demonstrated a new risk stratification scheme for stroke in HF patients.

16•- Melgaard L, Gorst-Rasmussen A, Lane DA, Rasmussen LH, Larsen TB, Lip GY. Assessment of the CHA2DS2-VASc score in predicting ischemic stroke, thromboembolism, and death in patients with heart failure with and without atrial fibrillation. JAMA. 2015;314:1030-8. This original paper reported the predictive value of $\mathrm{CHA}_{2} \mathrm{DS}_{2}$-VASc score for stroke in $\mathrm{HF}$ patients regardless of the presence of $\mathrm{AF}$.

17. Wolsk E, Lamberts M, Hansen ML, Blanche P, Køber L, TorpPedersen C, et al. Thromboembolic risk stratification of patients hospitalized with heart failure in sinus rhythm: a nationwide cohort study. Eur J Heart Fail. 2015;17:828-36.

18. Agarwal M, Apostolakis S, Lane DA, Lip GY. The impact of heart failure and left ventricular dysfunction in predicting stroke, thromboembolism, and mortality in atrial fibrillation patients: a systematic review. Clin Ther. 2014;36:1135-44.

19. Pullicino P, Homma S. Stroke in heart failure: atrial fibrillation revisited? J Stroke Cerebrovasc Dis. 2010;19:1-2.

20. Lip GY, Wrigley BJ, Pisters R. Anticoagulation versus placebo for heart failure in sinus rhythm. Cochrane Database Syst Rev. 2012: CD003336.

21. Cleland JG, Findlay I, Jafri S, Sutton G, Falk R, Bulpitt C, et al. The Warfarin/Aspirin Study in Heart failure (WASH): a randomized trial comparing antithrombotic strategies for patients with heart failure. Am Heart J. 2004;148:157-64.

22. Cokkinos DV, Haralabopoulos GC, Kostis JB, Toutouzas PK, investigators $\mathrm{H}$. Efficacy of antithrombotic therapy in chronic heart failure: the HELAS study. Eur J Heart Fail. 2006;8:428-32.

23. Massie BM, Collins JF, Ammon SE, Armstrong PW, Cleland JG, Ezekowitz M, et al. Randomized trial of warfarin, aspirin, and clopidogrel in patients with chronic heart failure: the Warfarin and Antiplatelet Therapy in Chronic Heart Failure (WATCH) trial. Circulation. 2009;119:1616-24.

24. Broderick J, Brott T, Kothari R, Miller R, Khoury J, Pancioli A, et al. The Greater Cincinnati/Northern Kentucky Stroke Study: preliminary first-ever and total incidence rates of stroke among blacks. Stroke. 1998;29:415-21.

25. Dunkman WB, Johnson GR, Carson PE, Bhat G, Farrell L, Cohn $\mathrm{JN}$. Incidence of thromboembolic events in congestive heart failure. The V-HeFT VA Cooperative Studies Group. Circulation. 1993;87: VI94-101.

26. Al-Khadra AS, Salem DN, Rand WM, Udelson JE, Smith JJ, Konstam MA. Antiplatelet agents and survival: a cohort analysis from the Studies of Left Ventricular Dysfunction (SOLVD) trial. J Am Coll Cardiol. 1998;31:419-25.

27. Group CTS. Effects of enalapril on mortality in severe congestive heart failure. Results of the Cooperative North Scandinavian Enalapril Survival Study (CONSENSUS). N Engl J Med. 1987;316:1429-35.

28. Hohnloser SH, Pajitnev D, Pogue J, Healey JS, Pfeffer MA, Yusuf $\mathrm{S}$, et al. Incidence of stroke in paroxysmal versus sustained atrial fibrillation in patients taking oral anticoagulation or combined antiplatelet therapy: an ACTIVE W Substudy. J Am Coll Cardiol. 2007;50:2156-61.

29. Al-Khatib SM, Thomas L, Wallentin L, Lopes RD, Gersh B, Garcia D, et al. Outcomes of apixaban vs. warfarin by type and duration of atrial fibrillation: results from the ARISTOTLE trial. Eur Heart J. 2013;34:2464-71.

30. Lauw MN, Vanassche T, Masiero S, Eikelboom JW, Connolly SJ. Pattern of atrial fibrillation and the risk of ischemic stroke- a systematic review and meta-analysis. Abstract 20413 at American Heart Association Scientific Session 2014 Chicago. Circulation. 2014;V(130):A20413.

31. Boriani G, Pettorelli D. Atrial fibrillation burden and atrial fibrillation type: clinical significance and impact on the risk of stroke and decision making for long-term anticoagulation. Vasc Pharmacol. 2016;83:26-35.

32. Boriani G, Laroche C, Diemberger I, Fantecchi E, Popescu MI, Rasmussen LH, et al. 'Real-world' management and outcomes of patients with paroxysmal vs. non-paroxysmal atrial fibrillation in Europe: the EURObservational Research Programme-Atrial Fibrillation (EORP-AF) General Pilot Registry. Europace. 2016;18:648-57.

33. Jorfida M, Antolini M, Cerrato E, Caprioli MG, Castagno D, Garrone P, et al. Cryptogenic ischemic stroke and prevalence of asymptomatic atrial fibrillation: a prospective study. J Cardiovasc Med (Hagerstown). 2016;17:863-9.

34. McMurray JJ, Ezekowitz JA, Lewis BS, Gersh BJ, van Diepen S, Amerena J, et al. Left ventricular systolic dysfunction, heart failure, and the risk of stroke and systemic embolism in patients with atrial fibrillation: insights from the ARISTOTLE trial. Circ Heart Fail. 2013;6:451-60.

35. van Diepen S, Hellkamp AS, Patel MR, Becker RC, Breithardt G, Hacke W, et al. Efficacy and safety of rivaroxaban in patients with heart failure and nonvalvular atrial fibrillation: insights from ROCKET AF. Circ Heart Fail. 2013;6:740-7.

36. Magnani G, Giugliano RP, Ruff CT, Murphy SA, Nordio F, Metra $\mathrm{M}$, et al. Efficacy and safety of edoxaban compared with warfarin in patients with atrial fibrillation and heart failure: insights from ENGAGE AF-TIMI 48. Eur J Heart Fail. 2016;18:1153-61.

37. Ferreira J, Ezekowitz MD, Connolly SJ, Brueckmann M, Fraessdorf M, Reilly PA, et al. Dabigatran compared with warfarin in patients with atrial fibrillation and symptomatic heart failure: a subgroup analysis of the RE-LY trial. Eur J Heart Fail. 2013;15: 1053-61.

38. Kang SH, Kim J, Park JJ, Oh IY, Yoon CH, Kim HJ, et al. Risk of stroke in congestive heart failure with and without atrial fibrillation. Int J Cardiol. 2017;248:182-7.

39. Hamatani Y, Iguchi M, Nakamura M, Ohtani R, Yamashita Y, Takagi D, et al. Incidence and predictors of ischemic stroke during hospitalization for congestive heart failure. Heart Vessel. 2016;31: 1154-61.

40. Vemmos K, Ntaios G, Savvari P, Vemmou AM, Koroboki E, Manios E, et al. Stroke aetiology and predictors of outcome in patients with heart failure and acute stroke: a 10-year follow-up study. Eur J Heart Fail. 2012;14:211-8.

41. Sobue Y, Watanabe E, Lip GYH, Koshikawa M, Ichikawa T, Kawai $\mathrm{M}$, et al. Thromboembolisms in atrial fibrillation and heart failure patients with a preserved ejection fraction (HFpEF) compared to those with a reduced ejection fraction (HFrEF). Heart Vessel. 2017.

42. McManus DD, Hsu G, Sung SH, Saczynski JS, Smith DH, Magid DJ, et al. Atrial fibrillation and outcomes in heart failure with preserved versus reduced left ventricular ejection fraction. J Am Heart Assoc. 2013;2:e005694.

43. Banerjee A, Taillandier S, Olesen JB, Lane DA, Lallemand B, Lip GY, et al. Ejection fraction and outcomes in patients with atrial fibrillation and heart failure: the Loire Valley Atrial Fibrillation Project. Eur J Heart Fail. 2012;14:295-301. 
44. Badheka AO, Rathod A, Kizilbash MA, Bhardwaj A, Ali O, Afonso L, et al. Comparison of mortality and morbidity in patients with atrial fibrillation and heart failure with preserved versus decreased left ventricular ejection fraction. Am J Cardiol. 2011;108: $1283-8$.

45. Kotecha D, Chudasama R, Lane DA, Kirchhof P, Lip GY. Atrial fibrillation and heart failure due to reduced versus preserved ejection fraction: a systematic review and meta-analysis of death and adverse outcomes. Int J Cardiol. 2016;203:660-6.

46. Kirchhof P, Benussi S, Kotecha D, Ahlsson A, Atar D, Casadei B, et al. 2016 ESC guidelines for the management of atrial fibrillation developed in collaboration with EACTS. Europace. 2016;18:160978 .

47. Isnard R, Bauer F, Cohen-Solal A, Damy T, Donal E, Galinier M, et al. Non-vitamin $\mathrm{K}$ antagonist oral anticoagulants and heart failure. Arch Cardiovasc Dis. 2016;109:641-50.

48. Passman R, Bernstein RA. New appraisal of atrial fibrillation burden and stroke prevention. Stroke. 2016;47:570-6.

49. Leclercq C, Padeletti L, Cihák R, Ritter P, Milasinovic G, Gras D, et al. Incidence of paroxysmal atrial tachycardias in patients treated with cardiac resynchronization therapy and continuously monitored by device diagnostics. Europace. 2010;12:71-7.

50. Caldwell JC, Contractor H, Petkar S, Ali R, Clarke B, Garratt CJ, et al. Atrial fibrillation is under-recognized in chronic heart failure: insights from a heart failure cohort treated with cardiac resynchronization therapy. Europace. 2009;11:1295-300.

51. Puglisi A, Gasparini M, Lunati M, Sassara M, Padeletti L, Landolina M, et al. Persistent atrial fibrillation worsens heart rate variability, activity and heart rate, as shown by a continuous monitoring by implantable biventricular pacemakers in heart failure patients. J Cardiovasc Electrophysiol. 2008;19:693-701.

52. Fernandez V, Béjot Y, Zeller M, Hamblin J, Daubail B, Jacquin A, et al. Silent atrial fibrillation after ischemic stroke or transient ischemic attack: interest of continuous ECG monitoring. Eur Neurol. 2014;71:313-8.

53. January CT, Wann LS, Alpert JS, Calkins H, Cigarroa JE, Cleveland JC, et al. 2014 AHA/ACC/HRS guideline for the management of patients with atrial fibrillation: executive summary: a report of the American College of Cardiology/American Heart Association Task Force on practice guidelines and the Heart Rhythm Society. Circulation. 2014;130:2071-104.

54. Camm AJ, Kirchhof P, Lip GY, Schotten U, Savelieva I, Ernst S, et al. Guidelines for the management of atrial fibrillation: the Task Force for the Management of Atrial Fibrillation of the European Society of Cardiology (ESC). Eur Heart J. 2010;31:2369-429.

55. Kennedy HL. Silent atrial fibrillation: definition, clarification, and unanswered issues. Ann Noninvasive Electrocardiol. 2015;20:51825 .

56. Dilaveris PE, Kennedy HL. Silent atrial fibrillation: epidemiology, diagnosis, and clinical impact. Clin Cardiol. 2017;40: 413-8.

57. Stamboul K, Zeller M, Fauchier L, Gudjoncik A, Buffet P, Garnier $\mathrm{F}$, et al. Prognosis of silent atrial fibrillation after acute myocardial infarction at 1-year follow-up. Heart. 2015;101:864-9.

58. Turakhia MP, Ullal AJ, Hoang DD, Than CT, Miller JD, Friday KJ, et al. Feasibility of extended ambulatory electrocardiogram monitoring to identify silent atrial fibrillation in high-risk patients: the Screening Study for Undiagnosed Atrial Fibrillation (STUDY-AF). Clin Cardiol. 2015;38:285-92.

59. Guenancia C, Pujos C, Debomy F, Malapert G, Laurent G, Bouchot $\mathrm{O}$. Incidence and predictors of new-onset silent atrial fibrillation after coronary artery bypass graft surgery. Biomed Res Int. 2015;2015:703685.

60. Lip GY, Nieuwlaat R, Pisters R, Lane DA, Crijns HJ. Refining clinical risk stratification for predicting stroke and thromboembolism in atrial fibrillation using a novel risk factorbased approach: the euro heart survey on atrial fibrillation. Chest. 2010;137:263-72.

61. Ye S, Qian M, Zhao B, Buchsbaum R, Sacco RL, Levin B, et al. CHA2DS2-VASc score and adverse outcomes in patients with heart failure with reduced ejection fraction and sinus rhythm. Eur J Heart Fail. 2016;18:1261-6.

62. Pullicino PM, Qian M, Sacco RL, Freudenberger R, Graham S, Teerlink JR, et al. Recurrent stroke in the warfarin versus aspirin in reduced cardiac ejection fraction (WARCEF) trial. Cerebrovasc Dis. 2014;38:176-81.

63. Di Tullio MR, Qian M, Thompson JL, Labovitz AJ, Mann DL, Sacco RL, et al. Left ventricular ejection fraction and risk of stroke and cardiac events in heart failure: data from the warfarin versus aspirin in reduced ejection fraction trial. Stroke. 2016;47:2031-7.

64. Ferreira JP, Girerd N, Gregson J, Latar I, Sharma A, Pfeffer MA, et al. Stroke risk in patients with reduced ejection fraction after myocardial infarction without atrial fibrillation. J Am Coll Cardiol. 2018;71:727-35.

65. Mujib M, Giamouzis G, Agha SA, Aban I, Sathiakumar N, Ekundayo OJ, et al. Epidemiology of stroke in chronic heart failure patients with normal sinus rhythm: findings from the DIG stroke sub-study. Int J Cardiol. 2010;144:389-93.

66. Melgaard L, Gorst-Rasmussen A, Rasmussen LH, Lip GY, Larsen TB. Vascular disease and risk stratification for ischemic stroke and all-cause death in heart failure patients without diagnosed atrial fibrillation: a nationwide cohort study. PLoS One. 2016;11: e0152269.

67. O'Connor CM, Hasselblad V, Mehta RH, Tasissa G, Califf RM, Fiuzat M, et al. Triage after hospitalization with advanced heart failure: the ESCAPE (Evaluation Study of Congestive Heart Failure And Pulmonary Artery Catheterization Effectiveness) risk model and discharge score. J Am Coll Cardiol. 2010;55:872-8.

68. Lee DS, Austin PC, Rouleau JL, Liu PP, Naimark D, Tu JV. Predicting mortality among patients hospitalized for heart failure: derivation and validation of a clinical model. JAMA. 2003;290: 2581-7.

69. Levy WC, Mozaffarian D, Linker DT, Sutradhar SC, Anker SD, Cropp AB, et al. The Seattle Heart Failure Model: prediction of survival in heart failure. Circulation. 2006;113:1424-33.

70. Melgaard L, Overvad TF, Skjøth F, Christensen JH, Larsen TB, Lip GYH. Risk of stroke and bleeding in patients with heart failure and chronic kidney disease: a nationwide cohort study. ESC Heart Fail. 2018;5:319-26.

71. Homma S, Thompson JL, Pullicino PM, Levin B, Freudenberger RS, Teerlink JR, et al. Warfarin and aspirin in patients with heart failure and sinus rhythm. N Engl J Med. 2012;366:1859-69.

72. Lip GY, Shantsila E. Anticoagulation versus placebo for heart failure in sinus rhythm. Cochrane Database Syst Rev. 2014: CD003336.

73•• Shantsila E, Lip GY. Antiplatelet versus anticoagulation treatment for patients with heart failure in sinus rhythm. Cochrane Database Syst Rev. 2016;9:CD003333. This review provides an overview of anticoagulation therapy in patients with $\mathrm{HF}$ in sinus rhythm

74. Liew AY, Eikelboom JW, Connolly SJ, O' Donnell M, Hart RG. Efficacy and safety of warfarin vs. antiplatelet therapy in patients with systolic heart failure and sinus rhythm: a systematic review and meta-analysis of randomized controlled trials. Int J Stroke. 2014;9:199-206.

75. Connolly SJ, Ezekowitz MD, Yusuf S, Eikelboom J, Oldgren J, Parekh A, et al. Dabigatran versus warfarin in patients with atrial fibrillation. N Engl J Med. 2009;361:1139-51. 
76. Granger CB, Alexander JH, McMurray JJ, Lopes RD, Hylek EM, Hanna M, et al. Apixaban versus warfarin in patients with atrial fibrillation. N Engl J Med. 2011;365:981-92.

77. Patel MR, Mahaffey KW, Garg J, Pan G, Singer DE, Hacke W, et al. Rivaroxaban versus warfarin in nonvalvular atrial fibrillation. $\mathrm{N}$ Engl J Med. 2011;365:883-91.

78. Giugliano RP, Ruff CT, Braunwald E, Murphy SA, Wiviott SD, Halperin JL, et al. Edoxaban versus warfarin in patients with atrial fibrillation. N Engl J Med. 2013;369:2093-104.

79. Xiong Q, Lau YC, Senoo K, Lane DA, Hong K, Lip GY. Nonvitamin $\mathrm{K}$ antagonist oral anticoagulants (NOACs) in patients with concomitant atrial fibrillation and heart failure: a systemic review and meta-analysis of randomized trials. Eur J Heart Fail. 2015;17: $1192-200$.
80. Zannad F, Greenberg B, Cleland JG, Gheorghiade M, van Veldhuisen DJ, Mehra MR, et al. Rationale and design of a randomized, double-blind, event-driven, multicentre study comparing the efficacy and safety of oral rivaroxaban with placebo for reducing the risk of death, myocardial infarction or stroke in subjects with heart failure and significant coronary artery disease following an exacerbation of heart failure: the COMMANDER HF trial. Eur J Heart Fail. 2015;17:735-42. 